\title{
Sala de Aula Invertida: Uma Inversão na Aula de Matemática
}

\author{
Inverted Classroom: An Inversion in the Mathematics Class \\ Aula invertida: Una Inversión en la Clase de Matemáticas
}

Recebido: 19/00/05/2021 | Revisado: 28/05/2021 | Aceito: 03/06/2021 | Publicado: 17/06/2021

\author{
Edilene França Pereira Sousa \\ ORCID: https://orcid.org/0000-0002-4450-8397 \\ Universidade Federal do Sul e Sudeste do Pará, Brasil \\ E-mail: edilene@unifesspa.edu.br \\ Ester Silva Chaves \\ ORCID: https://orcid.org/0000-0002-1165-7281 \\ Universidade Federal do Sul e Sudeste do Pará, Brasil \\ E-mail: esterchaves@unifesspa.edu.br \\ Valdineia Rodrigues Lima \\ ORCID: https://orcid.org/0000-0002-8605-1348 \\ Universidade Federal do Sul e Sudeste do Pará, Brasil \\ E-mail: valdineia@unifesspa.edu.br
}

\begin{abstract}
Resumo
No Ensino de matemática, cada vez mais tem se discutido a necessidade de aproximar a proporcionalidade com cotidiano do aluno e a Sala de Aula Invertida proporciona uma aprendizagem significativa que pode auxiliar nesse processo. Diante disso, o objetivo deste trabalho é apresentar argumentos que justifiquem o uso da Sala de Aula Invertida no ensino de proporcionalidade, por se tratar de uma metodologia acessível aos alunos e que acompanha o ritmo das tecnologias atuais. Esta pesquisa trata-se de um estudo de revisão de literatura de cunho qualitativo para fins de aprofundamento teórico sobre a temática. Os resultados apontam que a Sala de Aula Invertida intensifica a relação aluno e professor, muda o gerenciamento da sala de aula, permite condições para que o aluno pause e rebobine o professor e ajuda os alunos a superar as diferenças. Dessa forma, esta pesquisa defende a abordagem da proporcionalidade de maneira não mecanizada, e que seja mais próxima da realidade dos alunos, fazendo uso da Sala de Aula Invertida como instrumento potencializador da aprendizagem.
\end{abstract}

Palavras-chave: Ensino de Matemática; Proporcionalidade; Sala de aula invertida.

\begin{abstract}
In the teaching of mathematics, the need to bring proportionality closer to the student's daily life has been increasingly discussed and the Inverted Classroom provides significant learning that can assist in this process. Therefore, the objective of this work is to present arguments that justify the use of the Inverted Classroom in the teaching of proportionality, as it is a methodology accessible to students and that follows the pace of current technologies. This research is a qualitative literature review study for the purpose of theoretical deepening on the subject. The results show that the Inverted Classroom intensifies the relationship between student and teacher, changes classroom management, allows conditions for students to pause and rewind the teacher and helps students to overcome differences. In this way, this research defends the approach of proportionality in a non-mechanized way, and that is closer to the reality of the students, making use of the Inverted Classroom as an instrument to enhance learning.
\end{abstract}

Keywords: Mathematics teaching; Proportionality; Flipped classroom.

\section{Resumen}

En la enseñanza de las matemáticas, se ha discutido cada vez más la necesidad de acercar la proporcionalidad a la vida diaria del alumno y el Aula Invertida proporciona un aprendizaje significativo que puede ayudar en este proceso. Por tanto, el objetivo de este trabajo es presentar argumentos que justifiquen el uso del Aula Invertida en la enseñanza de la proporcionalidad, por ser una metodología accesible a los estudiantes y que sigue el ritmo de las tecnologías actuales. Esta investigación es un estudio de revisión de literatura cualitativa con el propósito de profundizar teóricamente sobre el tema. Los resultados muestran que el Aula Invertida intensifica la relación entre alumno y profesor, cambia la gestión del aula, permite que los alumnos pausen y retrocedan al profesor y ayuda a los alumnos a superar las diferencias. Así, esta investigación defiende el enfoque de proporcionalidad de forma no mecanizada, y más cercana a la realidad de los estudiantes, haciendo uso del Aula Invertida como instrumento para potenciar el aprendizaje.

Keywords: Enseñanza de las matemáticas; Proporcionalidad; Aula invertida. 


\section{Introdução}

A educação é um processo contínuo de construção de conhecimentos e valores, no mundo atual, cada vez mais se exige o desenvolvimento de competências necessárias para o exercício da cidadania. Nesse sentido, aprender matemática vai muito além do que aprender fórmulas e técnicas prontas e acabadas, visando apenas o seu uso imediato, é uma necessidade para "todos os alunos da Educação Básica, seja por sua grande aplicação na sociedade contemporânea, seja pelas suas potencialidades na formação de cidadãos críticos, cientes de suas responsabilidades sociais” (Brasil, 2017, p. 265).

A educação básica no Brasil é formada segundo a Lei de Diretrizes e Bases da Educação (LDB) nº 9394/96 pela educação infantil, ensino fundamental I e II e o ensino médio e ainda estabelece que os currículos do ensino fundamental devem ter uma base nacional comum (Brasil, 1996). Para atender tal demanda, no ano de 2017 foi homologado a BNCC do ensino fundamental, que estabelece:

Para o desenvolvimento das habilidades previstas para o Ensino Fundamental - Anos Finais, é imprescindível levar em conta as experiências e os conhecimentos matemáticos já vivenciados pelos alunos, criando situações nas quais possam fazer observações sistemáticas de aspectos quantitativos e qualitativos da realidade, estabelecendo interrelações entre eles e desenvolvendo ideias mais complexas. Essas situações precisam articular múltiplos aspectos dos diferentes conteúdos, visando ao desenvolvimento das ideias fundamentais da matemática, como equivalência, ordem, proporcionalidade, variação e interdependência. (Brasil, 2017, p. 298).

Evidenciando a importância da proporcionalidade para o desenvolvimento das habilidades da BNCC, sendo um tema relevante na formação das estruturas cognitivas dos estudantes, no desenvolvimento da aprendizagem de vários conceitos matemáticos, na aplicação em diversas áreas do conhecimento científico e no cotidiano das pessoas.

No entanto, esse conteúdo tem apresentado dificuldades para alunos e professores, uma possível explicação se deve ao fato de que seu ensino incide, de maneira geral, na apresentação mecanizada da regra de três (Gonçalves, 2010), sem possibilitar que os alunos possam adquirir o verdadeiro conhecimento de proporcionalidade.

Ao observar a necessidade de uma metodologia que auxiliasse no aprendizado da proporcionalidade, em que o aluno deixe ser um mero receptador, para que se torne "protagonista e aprenda de forma mais autônoma, com o apoio de tecnologias" (Pavanelo \& Lima; 2017, p.740), que possibilite um aprendizado mais participativo e significativo, optou-se pela metodologia da Sala de Aula Invertida e desencadeou-se a problemática desta pesquisa: Quais as vantagens que o professor de matemática tem ao inverter sua sala de aula no ensino de proporcionalidade? Por meio de uma revisão da literatura, de abordagem qualitativa, no intento de um aprofundamento com a temática está pesquisa tem como objetivo apresentar argumentos que justifiquem o uso da Sala de Aula Invertida no ensino de proporcionalidade, por se tratar de uma metodologia acessível aos alunos e que acompanha o ritmo das tecnologias atuais.

\section{Proporcionalidade e a Sala de Aula Invertida}

Um tema matemático fundamental tanto na escola como no cotidiano do aluno é a proporcionalidade, além de estar diretamente relacionada ao estudo da Matemática é um conteúdo com aplicações nas mais diversas áreas de conhecimento, como a geografia, engenharia, arquitetura, química, física, entre outros. Sendo um conteúdo integrador dos diferentes ramos da matemática e também fundamental para construir o conceito de função (Tinoco, 1996; 2011).

Ao longo dos anos os alunos do ensino fundamental vêm apresentando dificuldades no aprendizado da proporcionalidade, uma das explicações segundo Gonçalves (2010) é o fato de que seu ensino se incide, de maneira geral, na apresentação mecanizada da regra de três, sem possibilitar que os alunos possam adquirir o verdadeiro conhecimento de proporcionalidade, além da questão de o tema ser introduzido somente no $7^{\circ}$ ano do Ensino Fundamental II, privilegiando a regra de três como meio de resolução de problemas. 
Entretanto, com a Base Nacional Comum Curricular (BNCC) houve algumas mudanças e reorganização de alguns conteúdos, entre eles a proporcionalidade, estabelecendo a seguinte habilidade para o $6^{\circ}$ ano do ensino fundamental: "Resolver e elaborar problemas que envolvam porcentagens, com base na ideia de proporcionalidade, sem fazer uso da "regra de três", utilizando estratégias pessoais, cálculo mental e calculadora, em contextos de educação financeira, entre outros" (Brasil, 2017, p. 301). Essa habilidade, entre outras coisas, propõe o ensino da proporcionalidade, de forma que os alunos consigam compreender o conceito de porcentagem enquanto proporção.

Vários são os estudos em Educação Matemática e Educação em Ciências que tratam de proporções ou proporcionalidade. Vizolli (2001) realizou uma pesquisa sobre a aquisição do conceito de porcentagem enquanto proporção, explorando os diferentes registros de representação: numéricos (percentual, fracionário, decimal e proporcional), geométrico, em língua natural, tabela e gráfico, abordando os aspectos relativos ao sentido e ao significado operatório. Foi utilizada uma sequência didática em alunos da $6^{\mathrm{a}}$ série do ensino fundamental, obtendo resultados favoráveis.

Almeida (2015) realizou um estudo cujo objetivo era descrever os conceitos de razão e proporção através de situações presentes no cotidiano, estabelecendo relações da vida prática do leitor com a matemática ensinada nas escolas por análise e resolução de problemas. Apresentando modelos que podem ser utilizados por professores e aplicados em salas de aula do ensino fundamental.

Lima, Gomes e Oliveira (2020) na busca por novas abordagens no ensino da matemática apontam a música como elemento facilitador no ensino dos conceitos de razão e proporção, apresentando uma proposta de atividade pedagógica com um lápis e um violão, em que os alunos podem ouvir os sons das frações, para a construção de conhecimentos matemáticos, o que possibilita que estes compreendam a distinção entre razão e proporção, que muitas vezes é segundo os autores, mal interpretada.

Estes estudos mostram diferentes aspectos relativos à proporcionalidade, trazem a proporção como ferramenta para o cálculo de porcentagem, conteúdo matemático através de situações presentes no cotidiano, ou mesmo um conceito facilitador incorporado pela musicalidade. Entretanto, esta pesquisa apresenta como possibilidade a aplicabilidade da Sala de Aula Invertida, ao objeto de conhecimento proporcionalidade, por considerar relevante para a Educação Matemática, visto que ocorre na Educação Básica, e por se adaptar as necessidades do aluno moderno, tirando-o da posição de receptador para tornarse sujeito ativo na construção da aprendizagem.

Tinoco (1991, p.1) faz um alerta que ainda se encontra presente nos dias atuais, a "população em geral não retém quase nada da Matemática ensinada na escola, e, o que é mais grave, se orgulha disso". Entretanto, muitas mudanças já ocorreram e ainda estão ocorrendo no ensino de matemática, mas professores ainda são vistos por muitos como transmissões de conhecimento, o ensino de matemática ainda apresenta problemas como reprovação e evasão escolar por conta do repúdio a matemática por parte dos alunos.

$\mathrm{Na}$ busca de estudos sobre o desenvolvimento de novas técnicas e metodologias que possam mudar a realidade presente em muitas escolas, do professor como transmissor e da matemática como a disciplina temida pelos alunos, Gonzaga (2017) realizou uma pesquisa que teve como objetivo elaborar, aplicar e avaliar um processo para a implantação da metodologia Sala de Aula Invertida, propiciando suporte à aprendizagem colaborativa do Ensino de Matemática, sendo aplicada em uma turma do $9^{\circ}$ ano do Ensino Fundamental, obtendo resultados favoráveis na aplicação dessa metodologia.

Tobias (2018) investigou a utilização da Sala de Aula Invertida em uma turma do $9^{\circ}$ ano do ensino fundamental, nas aulas de proporcionalidade, em um viés de desenvolvimento do raciocínio proporcional, entretanto quanto a possibilidade de utilizar aulas gravas, não foram encontradas aulas disponíveis na internet que adequaram ao proposto da pesquisa, sendo necessário a gravação de materiais que foram disponibilizados posteriormente. A pesquisa apontou que esta metodologia é 
enriquecedora para propiciar a interação entre professores, alunos, escola e a família e ainda potencializa o ensino de matemática, ressaltam também quanto a importância de o professor enxergar sua sala de aula como um espaço de investigação.

Lima, Sousa e Sitko, (2021), realizaram uma revisão na literatura, na busca da caracterização e da definição de propostas pedagógicas de metodologias ativas para o Ensino de Matemática. As metodologias ativas estudadas foram Sala de Aula Invertida, a Instrução por Colegas e o Júri Simulado, o trabalho mostrou a importância de tais metodologias, assim como incentiva o uso de metodologias ativas de ensino e aprendizagem no Ensino de Matemática. Assim, no tópico que aborda a metodologia Sala de aula Invertida destacam que a intensão da Sala de aula Invertida é que o estudante tenha papéis ativos e torne-os o centro de seus próprios processos de aprendizagem. Para os autores, a Sala de Aula Invertida pode contribuir de várias formas para que o aprendizado aconteça desde "auxiliar os alunos tanto devido à flexibilidade de horário, pois podem acessar atividades e vídeos no ambiente on-line quando for conveniente, quanto devido à personalização do ensino que pode ser oferecida pelo professor, ao ser capaz de identificar, previamente à aula, quais são as dificuldades dos seus alunos" (Lima, 2011, p. 5).

Diante disso, é importante ressaltar que na Sala de Aula Invertida o professor assume o papel de mediador no processo de aprendizagem do estudante, sua função é auxiliá-los com suporte pedagógico, resolver as dúvidas coletivas e dedicar seu tempo em elaborar materiais e métodos que gere na sala de aula um ambiente em que "o aluno assuma um papel de aprendiz ativo e participante (não mais passivo e repetidor) de sujeito de ações que o levem a aprender e a mudar seu comportamento. Essas ações, ele as realiza sozinho, com o professor e com os seus colegas" (Masseto, 2015, p. 150).

O conceito de Sala de Aula Invertida é definido nesta pesquisa segundo Bergmann \& Sams (2016), como sendo basicamente uma inversão, o que era realizado em sala de aula será executado em casa, e o que tradicionalmente se realizava em casa, passa a ser desenvolvido em sala de aula. Os autores ressaltam ainda que a inversão da sala de aula não ocorre de uma única maneira, pois:

[...] não há essa coisa de a sala de aula invertida. Não existe metodologia específica a ser replicada, nem checklist a seguir que leve a resultados garantidos. Inverter a sala de aula tem mais a ver com certa mentalidade: a de deslocar a atenção do professor para o aprendiz e para a aprendizagem. Todo professor que optar pela inversão, terá uma maneira distinta de colocá-la em prática (Bergmann \& Sams, 2016, p.10).

Por outro lado, Valente (2014) destaca que alguns críticos discutem aspectos negativos da metodologia de Sala de Aula Invertida, apontando como um dos pontos negativos considerados mais problemáticos, o fato dos alunos não estudarem antes das aulas, não conseguindo assim, acompanharem o desenvolvimento da aula presencial, além de que, o modelo fica dependente das tecnologias e pode criar um ambiente de aprendizagem desigual, já que alguns alunos podem não ter acesso à internet em casa e ficariam em desvantagem mediante os colegas, que dispusessem dos recursos tecnológicos. Pontos estes, que devem ser considerados e trabalhos pelo professor.

\section{Abordagem Metodológica}

Esta pesquisa se caracteriza como uma abordagem qualitativa, tendo em vista que visa compreender e interpretar os dados coletados de forma subjetiva, buscando não uma quantificação, mas a síntese dos fatos. Para Pereira et al. (2018) é importante nos métodos qualitativos a interpretação por parte do pesquisador, assim como suas opiniões sobre o fenômeno que se estuda. Dessa forma, os pesquisadores que utilizam essa abordagem "buscam explicar o porquê das coisas, exprimindo o que convém ser feito, mas não quantificam os valores e as trocas simbólicas nem se submetem à prova de fatos, pois os dados analisados são não-métricos (suscitados e de interação) e se valem de diferentes abordagens" (Silveira \& Córdova, 2009, p. $32)$. 
Para alcançar o objetivo desta pesquisa foi realizado uma investigação teórica em busca de argumentos que justifiquem e fundamentem o uso da Sala de Aula Invertida no ensino de proporcionalidade, por se tratar de uma metodologia que se adequa facilmente aos ritmos das tecnologias atuais. Dessa forma, buscando responder a problemática de investigação foi realizado uma revisão da literatura, com a finalidade de levantar os referenciais sobre o tema proposto, e assim, construir uma contextualização para o problema de pesquisa e analisar as possiblidades encontradas na literatura para construção do referencial teórico da pesquisa (Alves-Mazzotti, 2002), fundamentando a discussão sobre o uso da metodologia da Sala de Aula Invertida no ensino de proporcionalidade.

\section{Sala de Aula Invertida: Uma Inversão na Sala de Aula}

Conta Soares (1998) que certa vez, o professor de literatura na escola média, norte americano Langdon Winner, questionou por curiosidade os seus alunos, sobre qual seria o livro de maior influência em suas vidas. Um terço dos estudantes não soube responder à pergunta, outro terço respondeu que nenhum livro os havia influenciado, e o terço restante fizeram citações de livros escritos por apresentadores de programas de televisão de grande audiência. Ou seja, fica nítido que esses alunos passaram uma grande parte de suas vidas expostos a programas de televisão, videogames e computadores, do qual o contexto cultural era baseado em códigos, recursos e ambientes virtuais, evidenciando um universo diferente do professor.

Em 2006, os professores de química Jonathan Bergmann e Aaron Sams (Bergmann \& Sams, 2016) começaram a lecionar juntos na Woodland Park High School, Colorado, Estados Unidos. Logo no início dos trabalhados notaram um problema, os alunos faltavam muito, no ano seguinte tiveram a ideia de gravar suas aulas, e postavam online para que os alunos faltosos pudessem acompanhar os demais, porém os alunos assíduos também se interessaram pelos vídeos. Consequentemente, por serem postados online, eram acessados facilmente por outros alunos e professores de química, repercutindo rapidamente, nascendo assim a Sala de Aula Invertida.

Com o sucesso da metodologia, educadores e pesquisadores empenharam-se em difundir o seu conceito com grandes reconhecimentos no meio da educação nos Estados Unidos e para isso, criaram a organização Flipped Learning Network (Tobias, 2018). A organização divulga conceitos sobre a aprendizagem invertida para que possa ser implantada pelos educadores com sucesso, as informações são trocadas entre os membros, o que possibilita a troca de experiências com objetivo de aprimoração da Sala de Aula Invertida.

Ao levar em consideração que no contexto do mundo tecnológico dos dias atuais, o professor de matemática precisa trabalhar com seus alunos, de forma eficiente e prazerosa o conjunto de informações, fórmulas e conceitos necessários para uma aprendizagem da matemática, todavia, nesse processo, o professor acaba encontrando desafios no ambiente escolar, uma vez que compete em grande desigualdade com a internet, videogames, computadores, tablets e outros dispositivos. Nesse sentido, a metodologia da Sala de Aula Invertida se aproxima da realidade dos alunos que estão sempre conectados com o mundo virtual, possibilitando o uso de instrumentos acessíveis em seu cotidiano.

Bergmann e Sams (2016), considerados os criadores da Sala de Aula Invertida, apontam como vantagens dessa metodologia:

- O papel ativo do aluno, que promove um senso maior de responsabilidade no seu próprio processo de aprendizagem;

- Flexibilização do tempo, que auxilia estudantes mais ocupados a acessarem o conteúdo em momentos mais adequados ao seu horário;

- Tempo maior em sala de aula para que o professor auxilie os estudantes com dificuldades no aprendizado;

- Rever os conteúdos, quantas vezes for necessário;

- Possibilita a intensificação na relação professor-aluno e aluno-aluno. 
Os autores apresentam também argumentos que embasam esta pesquisa, para justificar os motivos pelos quais o professor de matemática deveria inverter sua sala de aula, ressaltando que a Sala de Aula Invertida pode ser utilizada para outros conteúdos do ensino de matemática.

Figura 1: Argumentos para o professor inverter sua sala de aula.

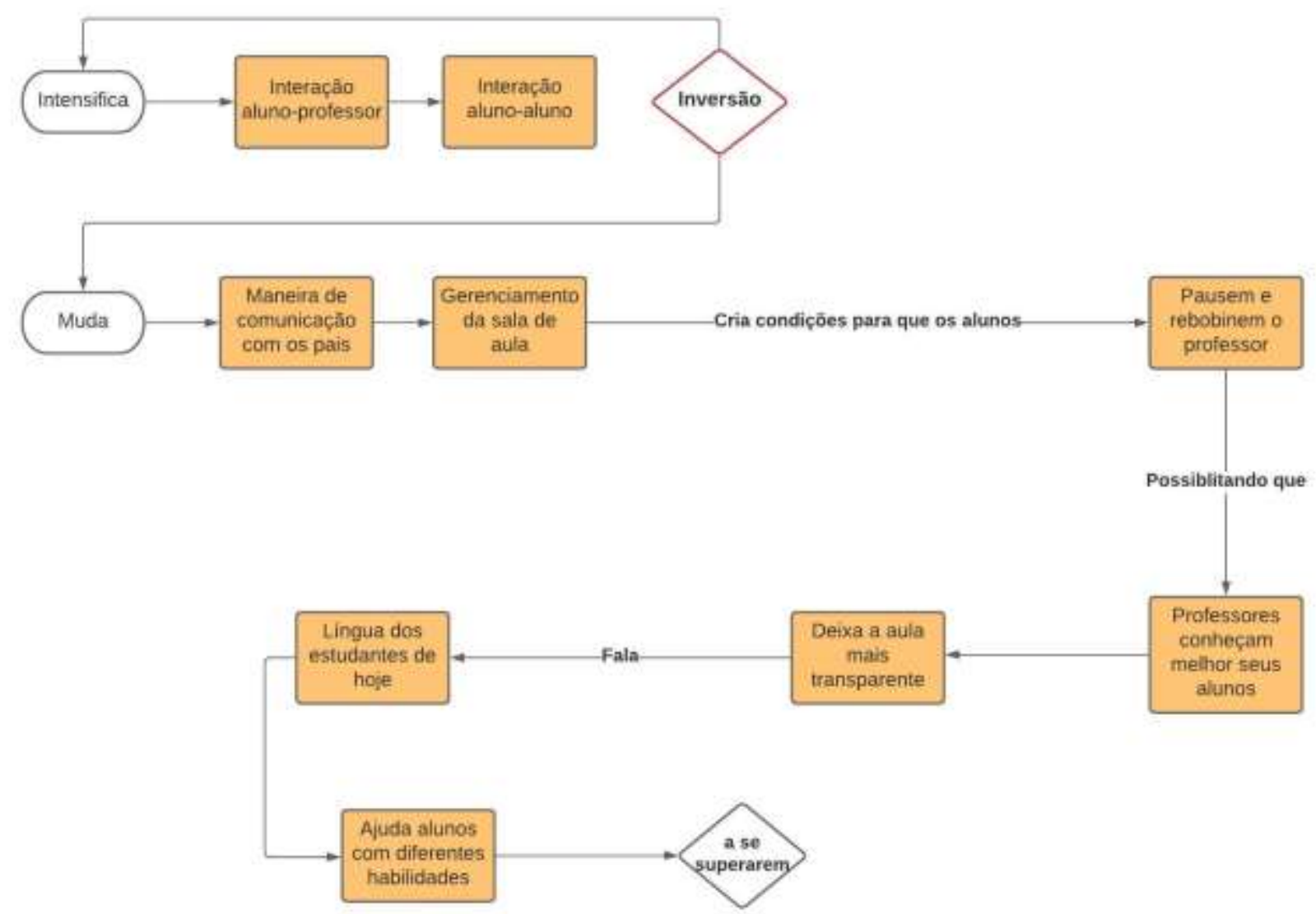

Fonte: Adaptado de Bergmann e Sams (2016, p.14).

Evidenciando que essa metodologia permite uma verdadeira diferenciação ao atender à diversidade dos alunos existente na sala de aula. Sendo responsável por uma inversão no modelo tradicional de ensino, a versão verticalizada do professor como transmissor de informações e do aluno como receptador, é invertida para o professor como condutor do ensino, proporcionando ao aluno um aprendizado mais amplo e completo.

A preocupação de que a escola repense sua função mediante o avanço das novas tecnologias, não é recente, Vizolli (2001) relata que:

Se por um lado, o avanço da Ciência, da Tecnologia e as mudanças na economia permitem que a maioria da população tenha acesso a televisão, [...] computador, por outro lado, a maioria das escolas brasileiras não dispõe de tais instrumentos, mas ela não pode fechar os olhos à realidade colocada. A existência e muitas vezes a facilidade, colocam os alunos em contato com tais instrumentos e isso exige que a escola (re)pense sua função, (re)estruture seus currículos e sua forma de agir, permitindo e garantido a utilização destes e de outros instrumentos necessários à aquisição do conhecimento, de forma que esses conhecimentos possam ser aplicados pelos sujeitos, não só na escola, mas também no meio social." (Vizolli, 2001, p. 2).

Embora a escola possa não dispor instrumentos necessários para acompanhar as novas tecnologias, não se pode segundo o autor, tapar os olhos para essa realidade. Trazendo essa discussão para a sala de aula, explorar metodologias que 
possibilitem a utilização de novas tecnologias, em especial as que estão ao alcance dos alunos, garante a estes a utilização de instrumentos que podem auxiliar na aquisição de conhecimentos que são aplicáveis não apenas na escola, mas também no ambiente social desse aluno.

Segundo Moran, Masetto e Behrens (2013) a inserção das tecnologias digitais no ensino provoca mudanças importantes na docência, sendo responsável por trazer novos desafios e possibilidades que transformam as escolas em espaços dinâmicos de aprendizagem, o que torna os estudantes mais motivados para o aprendizado e a pesquisa. Todavia, o professor precisa considerar os instrumentos que estão acessíveis aos alunos, tendo em vista que ao inverter a sala de aula, o aluno precisa ter acesso a internet para pesquisar o objeto de estudo.

Rodrigues (2020) estabelece três etapas para utilização da Sala de Aula Invertida, contato prévio do aluno com o conteúdo, em sala de aula promover a discussão e o debate entre os alunos e por fim, a consolidação da aprendizagem após a aula. Sendo assim, o professor de matemática pode para utilização dessa metodologia no ensino de proporcionalidade:

- Adotar uma sequência didática que se adeque a proposta da Sala de Aula Invertida;

- Definir qual o ambiente virtual de aprendizagem mais apropriado a realidade de seus alunos;

- Aplicar no ambiente virtual elementos de comunicação (salas/fórum de discussões em grupo), de cooperação (elaboração de resumos teóricos/Wiki), e de coordenação (painel de informes/aviso/desempenho, agenda virtual);

- Elaborar vídeos curtos e/ou adotar também vídeos prontos;

- Avaliar o nível de aprendizagem dos estudantes (questionários/relatórios);

- Analisar a contribuição da Sala de Aula Invertida para os alunos.

Assim, o professor passa a assumir um papel de orientador e apoiador nesse processo de aprendizagem, à medida que auxilia nas dúvidas quanto aos conceitos teóricos que foram estudados em casa pelos alunos (Pavanelo \& Lima, 2017). Fazendo com que o aluno passe a ser o protagonista e aprenda de maneira mais autônoma, apoiado pelas tecnologias digitais presentes em seu cotidiano.

\section{Considerações Finais}

Esta pesquisa buscou apresentar bases teóricas que discutem a Sala de Aula Invertida visando expor argumentos que justifiquem o seu uso no ensino de proporcionalidade, pois é uma metodologia que se adapta as tecnologias atuais se tornando acessível aos alunos.

A Sala de Aula Invertida é uma estratégia metodológica que permite o aluno desenvolver um papel mais ativo na construção da sua aprendizagem, pois possibilita maior responsabilização para aquisição do seu conhecimento. A flexibilização do tempo é um dos pontos positivos para usufruir dessa metodologia, uma vez que, os estudantes podem adequar o tempo de estudos com sua rotina diária, escolhendo assim horários mais propícios para acessar os conteúdos.

Outro ponto a ser destacado nessa metodologia, é a maior disponibilidade do professor em ajudar seus alunos, de acordo com as dificuldades especificas que eles apresentam no seu processo de aquisição do conhecimento, essa flexibilização ocorre devido o professor disponibilizar o conteúdo de forma prévia, e o tempo que seria gasto com introdução e apresentação do tema, será gasto com o esclarecimento de possíveis dúvidas.

Ademais, essa estratégia metodológica oportuniza ao aluno rever o conteúdo e rebobinar a fala do professor quantas vezes for necessário, ajustando o vídeo ao seu próprio tempo de aprendizagem. Além disso, a Sala de Aula Invertida possibilita a intensificação da relação entre professor-aluno e aluno-aluno, estreitando a interação entre esses sujeitos.

Como foi apresentado ao longo da pesquisa, a Sala de Aula Invertida tem grande potencial metodológico para a exploração do tema: Proporcionalidade. Pois, ocorrerá basicamente a inversão da aula, o que era realizado em sala de aula, 
passará a ser executado em casa, e o que habitualmente realizava-se em casa, passará a ser desenvolvido na sala de aula, porém essa maneira de inverter não é uma regra.

Ressaltando que, o ensino da proporcionalidade se apresenta em alguns espaços educacionais como um aprendizado mecanizado, pois essa relação entre grandezas é, muitas das vezes, ensinada de forma utópica da realidade dos alunos. Isso pode gerar desinteresse e desmotivação com a disciplina de matemática. Diante disso, a BNCC explicita como habilidade no Ensino da Matemática a prática da proporcionalidade ser abordado de diversas maneiras, sugerindo até mesmo a educação financeira.

Diante do exposto, defendemos a abordagem da proporcionalidade de maneira não mecanizada, e que seja mais próxima da realidade dos alunos, os professores podem fazer uso da Sala de Aula Invertida e utilizar como instrumento as seguintes abordagens: educação financeira, música, jogos pedagógicos, games entre outros. A fim de viabilizar o processo de ensino aprendizagem dos estudantes. Sendo assim, esperamos que este trabalho possa contribuir e orientar, de alguma maneira, professores e pesquisadores que tenham interesse em trabalhar com essa abordagem, ou mesmo no desenvolvimento de nossas pesquisas sobre a temática.

\section{Referências}

Almeida, R. G. (2015). Razão e proporção para além da sala de aula. (Dissertação de mestrado profissional). Universidade Federal de Juiz de Fora, Instituto de Ciências Exatas. PROFMAT- Mestrado Profissional em Matemática em Rede Nacional.

Alves-Mazzotti, A. J. A (2002). "Revisão bibliográfica” em teses e dissertações: meus tipos inesquecíveis - o retorno. In: BIANCHETTI, L.; MACHADO, A. M. N. (Org.). A bússula do escrever: desafios e estratégias na orientação de teses e dissertações (pp. 25-44). Cortez.

Bergmann, J., \& Sams, A. (2016). Sala de aula invertida: Uma metodologia ativa de aprendizagem. LTC, (1).

Brasil. (1996). Lei $n^{\circ}$ 9.394, de 20 de dezembro de 1996. Estabelece as diretrizes e bases da educação nacional. Presidência da República.

Brasil. (2017). Base Nacional Comum Curricular: Educação é a Base. Ensino Fundamental. MEC/CONSED/UNDIME.

Gonçalves, M. J. S. V. (2010). Raciocínio Proporcional: estratégias mobilizadas por alunos a partir de uma abordagem envolvendo a oralidade. (Dissertação de mestrado). Universidade Federal do Mato Grosso do Sul.

Gonzaga, H. L. H. (2017). Sala de Aula Invertida: uma abordagem colaborativa na aprendizagem de matemática. (Dissertação de mestrado). Universidade Federal de Juiz de Fora.

Lima, V., Gomes, A. C., \& De Oliveira, O. T. (2020). A música como proposta de atividade pedagógica no ensino de matemática. Pesquisas e Práticas Educativas, 1, 1-19.

Lima, V. R., Sousa, E. F. P., \& Sitko, C. M. (2021). Metodologias Ativas de Ensino e Aprendizagem: Sala de aula invertida, Instrução por colegas e Júri simulado no ensino de matemática. Research, Society and Development, 10 (5), 1-14.

Masseto, M. T. (2015). Mediação pedagógica e tecnologias de informação e comunicação. In Moran, José Manuel; Masseto, Marcos T.; Behrens, Marilda Aparecida. Novas Tecnologias e mediação pedagógica. Papirus.

Moran, J. M., Masetto, M. T., \& Behrens, M. A. (2013). Novas tecnologias e mediação tecnológica. Papirus, (21).

Pavanelo, E., \& Lima, R. (2017). Sala de aula invertida: a análise de uma experiência na disciplina de Cálculo I. Bolema, Rio Claro, 31 (58), 739-759.

Pereira A. S. et al. (2018). Metodologia da pesquisa científica. UFSM.

Rodrigues, R. (2020). Guia de metodologias ativas: com Google for Education. Hub Educat UFPE.

Silveira, D. T., \& Córdova, F. P. (2009). A pesquisa científica. Editora da UFRGS.

Soares, I. O. (1998). Gestión de la Comunicación en el Espacio educativo. Formación del Professorado en la Sociedad de la Información, 1, 33-46.

Tinoco, L. A. A. (1996). Razões e proporções. UFRJ.

Tinoco, L. A. A. (2011). Razões e Proporções (2a ed). UFRJ/IM.

Tobias, P. R. N. A. (2018). Sala de aula invertida na educação matemática: uma experiência com alunos do $9^{o}$ ano no ensino de proporcionalidade. (Dissertação de mestrado). Universidade Federal de Minas Gerais, Faculdade de Educação.

Valente, J. A. (2014). Blended learning e as mudanças no ensino superior: a proposta da sala de aula invertida. Educar em Revista. Educar em Revista, (Esp. n. 4), 79-97.

Vizolli, I. (2001). Porcentagem e Semiótica. (Dissertação de mestrado). Universidade Federal de Santa Catarina, Florianópolis. 